\title{
4.2 Entrevista a Mayra Rosario y a Lily González, participantes de la oferta extracurricular para Director Residente.
}

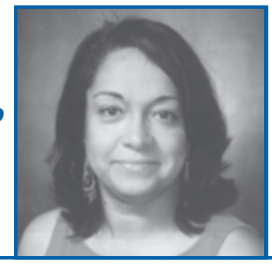

Mayra Rosario

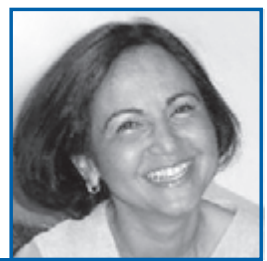

Lily González
Cada verano, la PUCMM elige a un profesor que acompaña a los estudiantes del programa de Conexiones Globales al Tompkins Cortland Community College, en Dryden, New York. Dicha persona puede asistir a cursos de su interés.

\section{SH: ¿Cuál es la función de ustedes dentro de la PUCMM?}

MR: He estado trabajando en la PUCMM por 25 años como profesora asistente, por asignatura, a tiempo completo y como coordinadora del área de Inglés. enseño. No es teoría de un libro, sino que yo lo viví y podría irme otra vez.

LG: Me interesaba acompañar a nuestros estudiantes para que su experiencia fuera más enriquecedora. Así mismo, tener una experiencia en una universidad de Estados Unidos para comprender más su cultura y mejorar mi trabajo como docente. Por otro lado, tener la posibilidad de tomar cursos de inglés y perfeccionar mis conocimientos de este idioma.

\section{"La experiencia me sirvió para mi vida profesional, para poder hablarles a mis alumnos sobre esa experiencia y estar en un país de la cultura de la lengua que yo enseño. No es teoría de un libro, sino que yo lo viví y podría irme otra vez".}

LG: Soy profesora de tiempo completo del Departamento de Humanidades y actualmente Directora Residente, en esta Institución, de los estudiantes del programas del Council on International Cooperation (CIC), enfocados en el área de Ciencias de la Salud.

\section{SH: ¿Qué les motivó a participar en este programa?}

MR: Quien me motivó fue Dra. Liliana de Montenegro, quien era en ese tiempo la Directora del Departamento de Lingüística Aplicada. La experiencia me sirvió para mi vida profesional, para poder hablarles a mis alumnos sobre esa experiencia y estar en un país de la cultura de la lengua que yo

\section{SH: ¿Qué facilidades económicas proporciona la Universidad para este programa?}

MR: Esta Institución mantuvo mi sueldo de profesora a medio tiempo y, además, me cubrió la estadía, el pasaje de ida y vuelta, y dinero para libros e imprevistos.

LG: El ticket aéreo y US $\$ 1,800.00$ dólares para viáticos y cubrir otros gastos de viaje. No sobra, pero es suficiente. Las excursiones son caras, no se puede ir a todas, el profesor puede llevar más dinero para comprar cosas que uno quiera. Además, la Universidad de Tompkins cubre el pago del seguro de salud y el alojamiento. Se vive en el campus en un apartamento compartido, ya sea por un estudiante, otro

1 Coordinadora de Comunicación para la Formación Docente en el Programa de Superación del Profesorado de la PUCMM 
profesor o alguien que trabaja ahí. También van profesores de Santo Domingo que dan clase en Estados Unidos. Sobre la comida, la calidad no es muy buena; por tanto, yo preparaba mis alimentos. Los de Tompkins estaban acostumbrados, los dominicanos sí se quejaban del sabor tan diferente al nuestro.

\section{SH: ¿Cómo se desarrolló la estadía allá?}

MR: La acogida fue muy buena y como yo hablo inglés, todo me salía muy bien. Esta experiencia le beneficia a una persona que quiera mejorar su inglés, pues casi nadie habla español. No obstante, nos faltó orientación para la llegada, ya que era día de fiesta en la Universidad. En cuanto al trato todo el mundo fue encantador, pues las autoridades saben lidiar con los deta- amistades nuevas que me paseaban y me invitaban a su casa.

LG: Normalmente, el cambio de ambiente en nuestros estudiantes influye en cambios de conducta, y ellos entran en conflicto con las reglas que hay allí. Nuestro perfil cultural caribeño es de hablar mucho $\mathrm{y}$, a veces, alto. Los estudiantes del programa pasan allá 2 meses y no siempre pueden salir a menudo, pues el transporte es costoso. Creo que necesitan más actividades extracurriculares donde canalizar su energía. Con respecto a la actitud de los estudiantes, éstos sí me respetaban, pues yo era el canal entre ellos y el equipo de Tompkins.

En Tompkins, un día se desarrollaba así: en la mañana iba a la oficina a darle segui-

\section{"En la mañana tomaba clases de Comunicación interpersonal y Funda- mentos del discurso, las cuales fueron excelentes. Actualmente hay más ofertas de cursos interesantes, y sabiendo inglés se puede ir de oyente a cualquier clase".}

lles de la cultura dominicana. Hubo un día en que nos reímos mucho en una clase y a partir de ahí se creó una buena empatía con los muchachos. El día en que volvíamos a Santo Domingo los estudiantes me abrazaban, emocionados.

En la mañana tomaba clases de Comunicación interpersonal y Fundamentos del discurso, las cuales fueron excelentes. Actualmente hay más ofertas de cursos interesantes, y sabiendo inglés se puede ir de oyente a cualquier clase.

En la tarde nos entreteníamos viendo televisión y en la noche, a veces, había charlas para los estudiantes, a las que yo asistía. Los fines de semana, el encargado de Asuntos Internacionales nos llevaba a algunos sitios de interés cultural. Siempre participé en excursiones ofrecidas a los estudiantes, lo que me permitió hacer miento a los estudiantes; a veces los llevaba al médico, en la tarde había reuniones de coordinación con el equipo de Tompkins, y yo los mantenía informados sobre las actividades nocturnas pues estas personas viven fuera del campus. También asistía a clases de inglés, cuando podía. El segundo verano que fui había tanto trabajo que no tenía tiempo para asistir a las diferentes actividades que se ofrecían.

En consecuencia, el perfil de un Director Residente implicaría ser una persona paciente, equilibrada, que sepa trabajar con estudiantes y haga el balance entre las dos culturas.

Los Asistentes de Residencia son jóvenes de la misma edad que los nuestros. La persona que va debe estar en contacto con ellos para que entiendan las formas de nuestra cultura. Ellos viven en el mismo edificio y 
están a cargo de poner el orden y organizar actividades. Éstos hacen bien su trabajo, pero también son jóvenes, se reúnen en las fiestas con los dominicanos, y a la hora de la disciplina, a veces, encuentran dificultades. Esto así porque los dominicanos tienen mucha energía y eso choca con la parsimonia de los de allá. Tompkins es un campus aislado, hay autobuses diarios a Ithaca, la ciudad cercana más grande, pero sólo hasta las 6 de la tarde. La otra alternativa es el taxi pero cuesta 12 dólares, y en el día ellos no siempre pueden salir.

SH: ¿Qué atractivos tiene el campus de Tompkins Cortland Community College para los directores residentes (instalaciones deportivas, biblioteca, área verde)?

LG: A mí me encanta la naturaleza y el
LG: Como Ithaca es una ciudad universitaria hay mucho movimiento, y lugares atractivos como museos y centros comerciales. Se ofrecen excursiones a los estudiantes a las Cataratas del Niagara, al Yankee Stadium, a un centro comercial, a un parque de diversiones. Pienso que hacen falta más actividades, cuyo precio esté al alcance de un público como los estudiantes, pues las que hay son muy costosas. Durante la primera semana, en Ithaca hay un festival de despedida de la primavera, pero esto no siempre coincide con el tipo de actividades que se organizan en relación a los intereses de nuestros estudiantes. No obstante, se podría también hacer un sondeo en cada grupo y organizar esas las actividades según sus preferencias.

A veces los muchachos van a Nueva York, por su cuenta, los fines de semana. Esto

\section{"A míme encanta la naturaleza y el campus tiene mucho verdor, instala- ciones deportivas, un gimnasio muy bueno, piscina, una biblioteca excelente donde tomar material prestado y conexión a redes. Hay una comunidad académica según tu área y puedes establecer relaciones institucionales".}

campus tiene mucho verdor, instalaciones deportivas, un gimnasio muy bueno, piscina, una biblioteca excelente donde tomar material prestado y conexión a redes. Hay una comunidad académica según tu área y puedes establecer relaciones institucionales.

SH: ¿Qué atractivos ofrece la ciudad (shopping mall, ciudades cercanas como New York, atractivos turísticos)?

MR: Dryden es un pueblo pequeño y acogedor; está cerca de los lagos y las cataratas. Por eso hace frío, el paisaje es precioso y la gente es cálida. Estuvimos de visita en la Universidad de Cornell, en Ithaca. Para mi sorpresa casi nadie conocía New York. Quien quiera puede rentar un carro y viajar por los alrededores. supone ocho horas de ida y vuelta.

\section{SH: ¿Recuerdan alguna anécdota interesante?}

MR: Un día le hice un mangú a una profesora que conocí allí y quedó fascinada. Otro día estaba caminando por el campus, y detrás de unas matas escuché un ruido muy extraño. Pensé que era un castor, pero luego supe que era un oso que merodeaba el campus. No volví a caminar sola.

Lo que más impacto me causó tuvo lugar en una de las clases que tomaba; el profesor era no-vidente $y$, sin embargo, el día del examen final había completo respeto, pues nadie molestaba ni se fijaba de algún compañero.

LG: La primera semana los muchachos hicieron una fiesta en el lago y los vecinos 
se quejaron con la Universidad. Nuestros estudiantes tienen muchas energías y es necesario.

\section{SH: ¿Qué beneficios pudieron obtener de esta experiencia en el extranjero?}

MR: La posibilidad de un intercambio directo con la cultura de mi segunda lengua que es parte de mi vida, de mi trabajo. Haber tomado esas materias allí, me abrió otras puertas. Gracias a la motivación y conocimientos que obtuve de una de ellas, ahora comienzo un segmento de 10 minutos en un programa de televisión, los sábados, en el canal 25. El espacio se llama "De corazón a corazón" y consiste en una conversación con una persona que es desconocida pero que ha dedicado parte de su vida a efectuar acciones de ayuda comunitaria y de sensibilidad humana.

LG: Tener más referentes de lo que es un conocer más la cultura norteamericana. De igual manera, pude participar de actividades interesantes en la Universidad, como un ciclo de cine latinoamericano y conferencias de temas diversos.

\section{SH: ¿Qué le recomiendan al Director Residente que lleve desde aquí?}

MR: Una greca de café, abrigos, sábanas y utensilios de uso personal. En cuanto a la ropa, con tres o cuatro jeans es suficiente.

LG: Que lleve una laptop. Esto facilita trabajar, entretenerse en la casa y comunicarse por email, pues ellos tienen sistema inalámbrico. También le recomendaría que lleve libros que le interese leer, souvenirs dominicanos o pequeños detalles para regalar a las nuevas amistades que se establecen.

"Otro día estaba caminando por el campus, y detrás de unas matas escuché un ruido muy extraño. Pensé que era un castor, pero luego supe que era un oso que merodeaba el campus".

programa de intercambio e interactuar con estudiantes en una convivencia cotidiana, me han hecho tener más empatía con mis estudiantes dominicanos y con los extranjeros que se quejan de la comida criolla.

SH: ¿Por qué razones recomendarían este programa a otros profesores?

MR: Para aprovechar esta magnífica oportunidad que ofrece la PUCMM. ¡Cuánto hubiera querido participar de este programa cuando era más joven para mejorar mi inglés!. Se podría ver hasta como unas vacaciones pagadas; por tanto, estoy muy agradecida de la Universidad al seleccionarme y participar de esta oferta extracurricular.

LG: Para involucrarse en temas de estudio, ampliar los contactos profesionales,

\section{SH: ¿En pocas palabras, cómo describirían su experiencia?}

MR: Llegué con muchas vivencias acumuladas, con más conocimiento cultural, y la piel más blanca por falta de sol. En fin, fue una experiencia maravillosa.

LG: Fue una experiencia retadora que contribuye con tu desarrollo personal, que invita a la reflexión acerca de la importancia de la empatía con los estudiantes, de las relaciones docente-alumno. Es una situación a veces maternal, pues te hace ver a los estudiantes como tus hijos.

\section{Cuaderno de Pedagogía Universitaria}

